\title{
The Effects of Mortality Salience on Disgust Sensitivity Among University Students, Older Adults, and Mortuary Students
}

\author{
Jonathan F. Bassett ${ }^{1, *}$ and Michael E. Sonntag ${ }^{2}$ \\ ${ }^{I}$ Department of Psychology, Lander University, USA \\ ${ }^{2}$ University of Maine at Presque Isle, USA
}

\begin{abstract}
The present study tested the Terror Management perspective on disgust by examining the effects of mortality salience on disgust sensitivity among 137 university students, 48 older adults, and 44 mortuary students preparing for a career in the funeral service industry. Participants were randomly assigned to a mortality salience, uncertainty salience, or television salience induction. Following a delay, participants completed the core disgust and contamination disgust subscales of the Disgust Scale Revised. University students reported more core disgust than did older adults and mortuary students. Women reported more core and contamination disgust than did men. Mortality salience led to increased disgust sensitivity among all three groups but only on a small number of items related to animals. The results suggest a limited role of terror management defenses in the experience of disgust in response to stimuli that remind people of their animal nature.
\end{abstract}

Keywords: Terror Management Theory, Disgust Sensitivity, Mortality Salience.

\section{THE EFFECTS OF MORTALITY SALIENCE ON DISGUST SENSITIVITY AMONG UNIVERSITY STUDENTS, OLDER ADULTS, AND MORTUARY STUDENTS}

The present paper examined the effects of experimentally inducing thoughts of death on disgust sensitivity among university students, older adults, and mortuary students. The goal of this examination was to further clarify the ongoing debate in the literature as to whether disgust is best conceptualized as an evolved mechanism to avoid biological threats such as ingesting potentially dangerous food or coming into contact with infectious agents [1-4] or as a culturally constructed mechanism to avoid psychological threats that remind people of their animal nature and consequently their mortality $[5,6]$. Support for the latter position comes from findings that reminders of death increased disgust sensitivity among university students [6]. Challenges to this position come from the findings that disgust sensitivity decreased with age and that reminders of death did not increase disgust sensitivity among participants with more accepting death attitudes [3]. The goal of the present study was to address some methodological limitations in these previous studies and to offer support for the partial role of disgust as a defense against death anxiety by showing that reminders of death increase disgust sensitivity in response to a limited number of stimuli even among older adults and mortuary students, both of whom typically hold more accepting death attitudes.

*Address correspondence to this author at the Department of Psychology, Lander University, 320 Stanley Ave, Greenwood, SC 29649, USA;

Tel: (864) 388-8740; E-mail: jbassett@lander.edu

\section{Disgust}

Rozin, Haidt, and McCauley [7] posited that, although disgust likely evolved as a way to protect human omnivores from bodily contamination through the oral incorporation of potentially harmful foods, the disgust mechanisms was coopted through cultural evolution to protect people from concerns about contamination of the soul. Their position is based on the idea that disgust is not elicited by specific sensory properties of stimuli but rather is a response to things that are ideologically offensive. If disgust were merely an evolved food rejection mechanism, then it should be elicited purely by sensory properties (e.g., disgust in response to bitter taste would facilitate avoiding the ingestion of potentially poisonous food). However, research participants were disgusted by the prospect of drinking a glass of their favorite juice that had previously come into contact with a sterilized roach and by the prospect of eating chocolate shaped like dog excrement although both situations involved no unpleasant sensory properties [8].

Haidt, Rozin, McCauley, and Imada [9] recognized that the primacy of animals and animal products as elicitors of disgust likely stemmed from their role in the transmission of parasites and infectious disease. They acquiesced that an evolutionary advantage would have been conferred to humans who were not only sensitive to the sensory properties of potential foods but also the contact history of those foods. However, they suggested that the lack of disgust responses in young children cast doubts on the adequacy of a conceptualization of disgust as purely an evolved mechanism for avoiding disease from ingesting dangerous food. Instead they argued that while disgust may have emerged to offer protection against biological threats, it is also a cultural phenomenon employed to offer protection against psychological 
threats. From this perspective, the ideological offensiveness running through all disgust eliciting stimuli is based on the idea that the body is a temple for the soul. Consequently, anything that reminds people of their purely corporeal nature (e.g., sex, eating, bodily waste) is disgusting unless it occurs in the proper cultural context of rituals which attempt to maintain the purity of the soul by distinguishing human behavior from that of other animals.

In developing their Disgust Scale as a measure of individual differences in disgust sensitivity, Haidt, McCauley, and Rozin [10] demonstrated that food, animals, body products, sex, body envelop violations, hygiene, and death were the main elicitors of disgust. They also identified an eighth factor called Magical Thinking that referred to the operation of the laws of sympathetic magic at work across all types of disgusting stimuli. Haidt et al. argued that the common theme running through the various elicitors of disgust was that they all served as reminders of the similarity between humans and animals. Consequently, they proposed that disgust in response to these stimuli represented a psychological defense in which people attempt to avoid the awareness of their animal nature. Haidt et al. suggested that death was the strongest reminder of human's similarity to other animals based on the finding that disgust in response to death related stimuli was one of subscales most predictive of overall disgust sensitivity and overall disgust sensitivity scores were positively correlated with fear of death. However, they acknowledged the possibility that the most troubling aspect of being an animal might be mortality and therefore reminders of human animal similarity might be problematic because they leave people prone to death anxiety. Disgust represents an aversion to stimuli that symbolically threaten the purity of the soul by implying that humans are similar to other animals and therefore no more enduring or valuable. They further suggested that such an analysis was consistent with the claim put forth in Terror Management Theory [11] that people ameliorate anxiety about personal extinction by constructing symbolic forms of identity which are viewed as more enduring and significant than the merely corporeal existence of nonhuman animals.

\section{Terror Management Theory}

Terror Management theorists [11] posited that the same uniquely human capacities for symbolic thinking and imagination that gave rise to the problem of death anxiety also gave rise to a solution in the form of culture. People are able to manage existential anxiety by embedding themselves in cultural worldviews which are the shared socially constructed interpretations of reality that allow people to view the world as an orderly, stable, and meaningful place. An individual's cultural worldview represents the system of beliefs, presumably shaped by his or her particular acculturation, that give meaning to existence. Cultural worldview ameliorates anxiety about the uncertain and unpredictable nature of premature death by affording people a sense of control and mastery over the environment. Further, cultural worldview attenuates anxiety about the inevitability of death by describing the means to achieve either literal or symbolic immortality and transcend death by identifying with something more enduring and meaningful than the corporeal self.
In a revision of their original position, Pyszczynski, Greenberg, and Solomon [12] have elaborated a more complex system of terror management mechanisms involving two distinct defensive processes that are activated in a particular temporal sequence. The first response to reminders of death is to push them out of conscious awareness by suppression or focusing on healthy lifestyle changes and one's likely longevity. This process, labeled proximal or direct defense, is successful for a while, but with delay and distraction death thoughts become hyper-accessible in the periphery of consciousness and threaten to reappear in conscious attention and produce anxiety. It is at this point that distal or symbolic defenses involving self-esteem striving and cultural worldview defense are utilized to dissipate the accessibility of death thoughts and prevent them from entering conscious awareness.

\section{Terror Management Perspective on Disgust}

Working from the perspective of Terror Management Theory, Goldenberg [5] posited that people are motivated to distance themselves from other animals in order to quell existential anxiety stemming from the uniquely human awareness of death. From this perspective, disgust is a symbolic or distal defense activated by reminders of human corporeality and vulnerability to death. By evidencing disgust, people try to elevate themselves above the status of other organisms in hopes of symbolically transcending their fate.

Goldenberg et al. [6] substantiated the TMT perspective on disgust by showing that experimentally inducing mortality salience led to a delayed increase in disgust sensitivity as measured using the Haidt et al. Disgust Sensitivity Scale. It is important to note that this study found an increase in disgust sensitivity only when participants had been reminded of their mortality and then distracted. This finding demonstrated that disgust was a distal or symbolic defense rather than a proximal or direct defense. Reminders of death were not motivating immediate disgust as a means to avoid potentially life threatening stimuli but rather were motivating delayed disgust as a means to symbolically distinguish humans as more valuable, special and enduring than other animals.

However, mortality salience produced a statistically significant increase in disgust sensitivity only in response to questions about animals and body products. Goldenberg et al. argued that mortality salience created an existential threat that motivated people to deny their similarity to other animals and that evidencing disgust in response to stimuli that blurred the human-animal distinction ameliorated that threat. They further argued that some of the items on the Disgust Scale were related to moral revulsion or sensory distaste rather than reminders of human-animal similarity; therefore, mortality salience led to increased disgust sensitivity only on the body product and animal subscales because these subscales contained items that were the strongest reminders of human-animal similarity.

Additional support for the Terror Management perspective on disgust comes from the finding that graphic visual images that powerfully elicited disgust increased the accessibility of death related thoughts and that milder disgust eliciting stimuli (reading items from the Disgust Scale) also increased the accessibility of death related thoughts but only 
when coupled with essays priming human similarity to other animals [13].

\section{Challenges to the Terror Management Perspective on Disgust}

Although there is some evidence for the TMT perspective on disgust, critics of this perspective think disgust is best conceptualized as an evolved mechanism to prevent disease and maladaptive sexual behavior [3]. Compelling evidence for the idea that disgust is an evolved disease avoidance mechanism comes from findings based on a very large sample of respondents to an online-survey [1]. This research demonstrated that disgust was stronger to disease relevant images (e.g., parasites, bodily fluid, feverish face, laceration with pus) than to similar images less relevant to disease transmission (e.g., non-parasitic insects, blue slime, nonfeverish face, laceration without pus). Also consistent with the evolutionary perspective, these authors found that respondents were more disgusted by the bodily fluids of strangers than those of close relatives, presumably because strangers are more likely to carry non-native pathogens. Further, women reported more disgust than men, presumably because women evolved a more sensitive disgust reaction due to the risk pathogens posed to the developing fetus.

Additional support for the evolutionary perspective on disgust comes from the finding that women's sexual disgust varied across the menstrual cycle with the greatest disgust occurring around times of highest likelihood of conception [2]. These authors argued that this finding was difficult to account for from the Terror Management perspective and instead indicated that disgust was an evolved mechanism to prevent sexual activity that would lead to less than optimal gene propagation.

Fessler and Navarrette [3]attempted to directly repudiate the Terror Management perspective on disgust by examining age differences in disgust and by examining the effects of mortality salience on disgust in populations with more accepting death attitudes. These authors hypothesized that if disgust was motivated by a desire to deny one's vulnerability to mortality then disgust sensitivity ought to increase with age as the inevitability of personal death becomes increasingly salient. Based on data from two large internet samples, Fessler and Navarrette found that disgust sensitivity in response to death related items from the Haidt et al. Disgust Scale actually decreased with age. These authors interpreted their findings as inconsistent with Terror Management Theory.

Fessler and Navarrette [3] also questioned the universality of psychological defenses against death advocated by Terror Management theorists. They hypothesized that people in cultures with more accepting attitudes towards death would not respond to mortality salience with increased disgust sensitivity. They tested this hypothesis in a sample of rural Costa Ricans. Consistent with their hypothesis, mortality salience had no effect on disgust sensitivity in response to stimuli related to death, body products, or animals. Therefore, they argued that the effects of mortality salience on disgust sensitivity were limited only to participants in industrialized western cultures characterized by high levels of death denial. Consequently, they suggested that the evolu- tionary perspective on disgust was superior to the Terror Management perspective given the former's greater generalizability.

Although Fessler and Navarrette [3] concluded that their results called into question the validity of the Terror Management perspective on disgust, there are some theoretical and methodological issues in their research that must be addressed before such a conclusion is warranted. Regarding the relation of age and death related disgust, Fessler and Navarrette mischaracterized the prediction of TMT by asserting that death anxiety would increase with age as would the use of psychological defenses to protect against this increased anxiety. In contrast to this assumption, research on the relation between death anxiety and age shows that the elderly are less anxious about death than the young [14-16]. In fact, Terror Management theorists [17] made a prediction about age and psychological defense that was opposite of the one ascribed to Terror Management by Fessler and Navarrette. These authors [17] suggested that given older adults' seeming lack of death anxiety in the face of increased death salience and the diminished viability of the typically studied defenses involving self-esteem and cultural worldview defense, some alternative coping mechanisms must be at work. Likely, older adults switch from responding to reminders of mortality with worldview defense to alternative responses including self-detachment, generativity, increased complexity of self-concept, and life review.

As a test of the hypothesis that older adults would be less defensive than younger adults in response to reminders of death, researchers [18] directly compared the effects of mortality salience on cultural worldview defense in younger and older adults. They found that mortality salience relative to dental pain salience increased the harshness of reactions to social violators among younger adults. In contrast, among older adults reactions to social transgressors did not differ across the two conditions. These authors [18] interpreted their results as evidence that older adults either view death as a more natural and less threatening event or they have adopted other forms of maintaining psychological well-being that are less likely to induce negative affect. They suggested that the latter explanation is consistent with work on Socioemotional Selectivity Theory [19] that shows that older adults are good at maintaining a sense of well-being by regulating affect through focusing on positive and avoiding negative aspects of experience.

Whereas Fessler and Navarrette [3] interpreted their finding that death disgust decreases with age as incompatible with Terror Management theory, this finding is in fact consistent with previous evidence that attitudes towards death become less negative with age [14-16] and is congruent with the Terror Management hypothesis that older adults become more adroit at dealing with existential anxiety [17]. What is needed is an examination of the effects of mortality salience on disgust sensitivity in older adults. Whereas previous research [18] found that mortality salience did not increase cultural worldview defense among older adults, it is not clear whether this means that older adults would not respond to mortality salience with other types of defenses. If older adults still need protection against the awareness of mortality, but avoid using cultural worldview defense as a means of 
accruing that protection because of the concomitant negative affect involved, then in response to mortality salience they may still employ symbolic defenses that do not involve expressing negativity towards others . Expressing disgust sensitivity in response to reminders of human-animal similarity as a means of establishing the enduring significant of personal identity would be one such defense.

Fessler and Navarrette [3] concluded that the Terror Management perspective on disgust does not generalize to groups with more accepting death attitudes. However, methodological differences between the Goldenberg et al. study [6] and the Fessler and Navarrette study [3] make interpretation of their different findings difficult. First, Goldenberg et al. [6] intentionally removed death related items from their measure of disgust sensitivity because they hypothesized that mortality salience would produce an increase in disgust sensitivity only following delay or distraction and were concerned that the inclusion of death related items would refocus conscious attention on mortality and confound the manipulation. In contrast, Fessler and Navarrette included the death related items in their measure of disgust sensitivity. Therefore, it is possible that their null results reflect the fact that mortality was salient while disgust to non-death related stimuli was being measured. Second, the Costa Rican sample described by Fessler and Navarrette differed from the American sample described by Goldenberg et al. on dimensions other than familiarity with death. For example, the American sample was composed of university students, whereas the Costa Rican sample had on average only a primary school education level. Consequently, the null effect of mortality salience in the Costa Rican sample might be attributable to factors other than greater familiarity with death. Third, Fessler and Navarrette used oral interview techniques, whereas most terror management research has employed written questionnaires. Therefore, the failure to observe mortality salience effects in the Costa Rican sample might be a procedural artifact of the fact that the mortality salience induction was oral rather than written. A fairer test of the possible moderating role of individual differences in death attitudes would involve examining delayed disgust only to items that did not specifically mention death following the traditional written mortality salience induction.

\section{Goals of the Present Study}

The goal of the present study was to further test the possible link between death concerns and disgust by examining the effects of mortality salience on disgust sensitivity among groups that differ in their chronic trait levels of death anxiety (university students, mortuary students, and older adults). The present study is a conceptual replication of work by Goldenberg et al. [6] and Fessler and Navarrette [3] with a few methodological changes.

Although Goldenberg et al. [6] made a compelling case for the role of terror management in the disgust responses of university students, their study was limited due the use of writing about television as the control condition, which made it difficult to conclude that the effect of mortality salience was due to death specific concerns and not general negative affect. Some have suggested that what is most threatening about reminders of mortality is the uncertainty about the exact time and nature of one's death and consequently that concerns about death could be subsumed into a larger more general class of existential threats related to uncertainty [20]. These authors argued that the typical effects of mortality salience reported by Terror Management theorists might not be specific to death but might reflect an increased need for cognitive structure that would be elicited by any reminders of uncertainty. Consistent with this position, research has demonstrated that uncertainty salience has the same effects as mortality salience on reactions to social deviants who threaten cultural worldview [21,22]. The present study examined the effects of mortality salience on disgust sensitivity not only in comparison to a neutral television condition but also to an uncertainty condition. The finding that mortality salience but not uncertainty increases disgust sensitivity relative to thinking about television would strengthen the case for the Terror Management perspective.

The present study also furthered the analysis of Fessler and Navarrette [3] about the relation between age and disgust sensitivity and how this relation reflects on Terror Management Theory. Although Fessler and Navarrette found that death disgust decreased with age, this finding is consistent with previous research on death attitudes in older adults [1416] and is not incompatible with Terror Management Theory [17]. The present study examined the effects of mortality salience on disgust sensitivity among older adults in response to disgust eliciting domains not directly related to death. Although previous research [18] found no effect of mortality salience on cultural worldview defense among older adults, disgust sensitivity in response to reminders of human-animal similarity represents a different kind of defense because it does not involve increased negative affect directed towards others. Therefore, the authors of the present study hypothesized that older adults, just like younger participants, might show a delayed increase in disgust sensitivity in response to reminders of death.

The present study also furthered Fessler and Navarrette's [3] analysis of the potential role that attitudes about death might have in moderating the effects of mortality salience on disgust sensitivity. Fessler and Navarrette interpreted the finding that mortality salience did not increase disgust sensitivity among rural Costa Rican participants as evidence that the Terror Management perspective does not apply to groups with more accepting death attitudes. However, such a conclusion is made problematic by their inclusion of death related disgust items which may have masked distal terror management defenses by reactivating proximal suppression.

The current study examined the effects of mortality salience, only on disgust elicitors that did not explicitly mention death, among mortuary students preparing for a career in funeral service. Mortuary students were chosen because previous research has shown that they are less anxious about death than university students $[23,24]$. No research known to the authors has examined psychological defenses of any kind in response to mortality salience among mortuary students. If mortality salience effects occur only among participants with death denying attitudes, then these effects should not be observed among mortuary students. However, such a prediction is not clear cut because, from the perspective of Terror Management Theory, the low levels of death anxiety reported by mortuary students could alternatively reflect their adept use 
of psychological defense, in which case they should show the same elevated disgust sensitivity in response to reminders of death observed in university students.

\section{METHOD}

\section{Participants}

A total of 229 participants were recruited from five different locations: two university student groups, two older adult groups, and one group of mortuary science students. The mortuary group consisted of 44 students enrolled in mortuary science classes at Gupton-Jones Funeral College. Gupton-Jones Funeral College, located in Decatur Georgia, offers an 18 months associate of science degree in funeral service which prepares graduates to work in the funeral industry. Of these participants, 19 were men and 25 were women. These participants ranged in age from 18-54 years $(M=28.91, S D=9.62)$. As an incentive, these participants received a donation in the amount of $\$ 10$ made in their name to the campus student activities fund.

The university student group consisted of 39 students recruited from psychology classes at Lander University and 98 students recruited from psychology classes at the University of Maine Presque Isle (UMPI). Of the Lander participants, 13 were men and 26 were women. These participants ranged in age from $18-40$ years $(M=20.56, S D=4.30)$. Of the UMPI participants, 34 were men and 63 were women. These participants ranged in age from 18-42 years $(M=$ $21.69, S D=4.89$ ). As an incentive, all student participants received extra credit towards their course grade.

The older adult group consisted of 36 participants recruited from continuing education classes at Furman University's learning in retirement program (FULIR) and 12 participants recruited from the Seniors Achieving Greater Education (SAGE) program at UMPI. FULIR is a membership group associated with Furman University in upstate South Carolina and allied with the Elderhostel Institute Network that promotes life- long learning by offering a variety of courses and programs to older adults. The participants from FULIR were 9 men and 27 women ranging in age from 5383 years $(M=69.14, S D=7.75)$. The SAGE program is a membership group associated with UMPI and open to adults age 50 and older interested in life-long learning in the areas of arts, sciences, current events, and foreign affairs. The participants from SAGE were 3 men and 9 women ranging in age from 66-81 years $(M=74.58, S D=5.58)$. As an incentive, FULIR participants received payment in the amount of $\$ 10$. No incentive was offered to SAGE participants. All participants were treated according to the ethical principles and guidelines of the American Psychological Association [25].

\section{Materials and Procedure}

Data were collected in group settings at the beginning of regularly scheduled class meeting times. After announcing the opportunity to participate in the research, the researchers distributed consent forms and questionnaire packets to all interested persons. In the first section of the questionnaire, participants provided demographic information and responded to the experimental manipulation. Participants were randomly assigned to either a mortality salience or one of two control conditions. Participants in the mortality salience condition responded to two open ended questions about their own death [26]. Participants in the aversive control condition responded to two parallel questions about uncertainty [27]. Participants in the neutral control condition responded to two parallel questions about watching television. Watching television has been used as a neutral topic for comparison with mortality salience in numerous studies [26, 27]. However, it has been suggested that it may be necessary to have two control conditions [28]. The uncertainty condition allows for a comparison of the influence of death thoughts relative to other unpleasant thoughts. However, the television condition allows the researcher to examine the possibility that both mortality salience and uncertainty produced some effect on the dependent variable.

In the third section of the questionnaire, a delay was inserted between the manipulation and the dependent variable by having all participants complete a brief measure of their current mood called the Positive and Negative Affect Scale [29] and an innocuous word search puzzle [30]. These measures served to create a delay between the manipulation and the dependent variable because previous research has found that mortality salience produces the strongest distal defenses following a delay [31]. The Positive and Negative Affect Scale was also included to rule out the possibility that any effect of mortality salience was due to general negative affect.

In the fourth section of the questionnaire, participants completed the dependent measure of disgust sensitivity. Disgust sensitivity was measured using items from the Disgust Scale Revised (DSR) [10, 32]. The original DS [10] contained 32-items that assessed disgust in eight domains (food, animals, body-products, hygiene, sex, body envelope violations, death, and sympathetic magic). Based on research by Olatunji et al. [32], the DSR dropped seven of the original items due to their poor psychometric properties. Olatunji et al reported that the 25 -item DSR measures three factors rather than eight. They labeled the first factor as core disgust. This factor contained 12-items related to disgust in response to food, animals, and body products. The core disgust subscale had adequate internal consistency (Cronbach's $\alpha=$ .74). They labeled the second factor animal reminder disgust. This factor contained 7 items related to disgust in response to death and body envelope violations. The animal reminder disgust subscale had adequate internal consistency (Cronbach's $\alpha=.78$ ). They labeled the third factor contamination based disgust. This factor contained 6 items related to disgust in response to perceived contamination through the laws of sympathetic magic. The contamination disgust subscale had less than desirable internal consistency (Cronbach's $\alpha=.61)$.

In the present study, participants rated, on a scale from 04 , how disgusted they would feel in response to the 12-item core disgust subscale and 5-items from the contamination subscale of the DSR. The 7-items from the animal reminder subscale of the DSR were not included. Although Olatunji et al. labeled the third subscale animal reminders the items are actually related to death and body envelope violation. Therefore, these items were deleted because the authors were concerned that including them might have made mortality salient and confounded the experimental manipulation. This 
exclusion is consistent with the procedure employed by Goldenberg et al. [6], in which items from the death subscale of the original DS were dropped. However, we took the additional step of excluding the items related to body envelope violation because Goldenberg et al. [6] found no effect of mortality salience on these items and speculated that these items may have reactivated proximal defenses rather than the distal defenses that are purported to increase disgust. In addition, one item from the contamination subscale of the DSR was not included because it contained content explicitly related to death: 'It would bother me to sleep in a nice hotel room if I knew that a man had died of a heart attack in that room the night before.' Therefore, in the current study, participants responded only to the 12 -items from the core disgust subscale of the DSR and to 5-items from the contamination disgust subscales of the DSR which contained no explicitly death related themes. In the present study the Cronbach's $\alpha$ for the 12-item core disgust scale was .79. In the present study the Cronbach's $\alpha$ for the 5-item contamination subscale was .57 .

\section{RESULTS}

Core disgust sensitivity scores were subjected to a condition (MS/uncertainty/television) $\mathrm{x}$ group (student/older adult/mortuary) x gender (men/women) ANCOVA with negative affect as a covariate. There was a main effect for gender, $F(1,207)=40.7, p<.001$, with women reporting more core disgust $(M=28.78, S D=7.83)$ than men $(M=$ $20.13, S D=8.36)$. There was also a main effect for group, $F(1,207)=3.9, p<.05$. Planned contrasts revealed that university students reported more core disgust $(M=27.29$, $S D=8.92)$ than did older adults $(M=23.96, S D=7.72)$ and mortuary students $(M=23.34, S D=8.97), t(182.41)=3.0$, $p<.01$, but older adults and mortuary students did not differ in their reported core disgust, $t(82.51)=0.33, p=.74$. None of the other main or interaction effects approached statistical significance. The effect of the manipulation was in the predicted direction with nominally higher scores in the mortality salience condition than in the other two conditions (see Table 1), but this difference did not reach statistical significance, $F(2,207)=1.4, p=.26$.

Contamination disgust sensitivity scores were subjected to a condition (MS/uncertainty/television) $\mathrm{x}$ group (student/older adult/mortuary) x gender (men/women) ANCOVA with negative affect as a covariate. The only statistically significant effect was a main effect for gender, $F$ $(1,207)=258.6, p<.001$, with women reporting more contamination disgust $(M=8.32, S D=3.75)$ than did men $(M=6.32, S D=3.81)$.
Given that Goldenberg et al. [6] reported that mortality salience increased disgust sensitivity only on items related to body products and animals, we decided a more sensitive test of the Terror Management perspective on disgust would involve analyzing scores based on DSR items retained from the body product and animal subscales of the original DS [10]. The DSR retained three of the four items from the original body products subscale of the DS. Responses to these three items were summed to create a body product disgust sensitivity score (Cronbach's $\alpha=.56$ ). The DSR retained all four items from the original animal subscale of the DS. Responses to these four items were summed to create an animal disgust sensitivity score (Cronbach's $\alpha=.69$ ). The resulting body products and animal disgust sensitivity scores were subjected to separate condition (MS/uncertainty/ television) $\mathrm{x}$ group (student/older adult/mortuary) $\mathrm{x}$ gender (men/women) ANCOVAs with negative affect as a covariate.

The analysis of body product disgust sensitivity revealed no significant effect of mortality salience and no significant interaction of mortality salience with gender or group $\left(F_{\mathrm{S}}<\right.$ 1.4). The analysis of animal disgust sensitivity revealed the predicted main effect for mortality salience, $F(1,207)=3.6$, $p<.05$. Planned contrasts revealed that participants in the mortality salience condition reported more animal disgust sensitivity $(M=8.81, S D=3.96)$ than did participants in the uncertainty $(M=7.68, S D=3.97)$ and television conditions $(M=7.78, S D=4.20), t(169)=2.0, p<.05$, but participants in the uncertainty and television conditions did not differ from each other, $t(147.9)=0.14, p=.88$. However, mortality salience did not interact with gender or group $(F \mathrm{~s}<1.5)$. Although mortality salience increased disgust sensitivity only in response to animals, this effect emerged among university students, older adults, and mortuary students (see Table 2).

\section{DISCUSSION}

The results of the present study offer limited support for the Terror Management perspective on disgust. Mortality salience did result in greater disgust sensitivity compared to thinking about uncertainty or watching television but only on the four items related to animals. Therefore, the idea that disgust serves as a symbolic defense against reminders of mortality seems applicable only to a small subset of the types of stimuli that elicit disgust. This finding seems consistent with Fessler and Navarrete's [3]criticism of Terror Management Theory as offering an inadequate account for the full scope of disgust responses. However, Terror Management theorists seem aware of the fact that their perspective does

Table 1. The Effects of Mortality Salience on Core Disgust Sensitivity

\begin{tabular}{|c|c|c|c|}
\hline & Television Salience & Uncertainty Salience & Mortality Salience \\
\hline \hline & $M(S D)$ & $M(S D)$ & $M(S D)$ \\
\hline University Students & $26.70(8.69)$ & $26.73(9.18)$ & $28.32(9.07)$ \\
\hline Older Adults & $22.83(7.75)$ & $23.23(7.51)$ & $25.93(8.01)$ \\
\hline Mortuary Students & $25.20(11.35)$ & $20.57(10.29)$ & $24.07(6.62)$ \\
\hline
\end{tabular}


Table 2. The Effects of Mortality Salience on Animal Disgust Sensitivity

\begin{tabular}{|c|c|c|c|}
\hline & Television Salience & Uncertainty Salience & Mortality Salience \\
\hline \hline & $M(S D)$ & $M(S D)$ & $M(S D)$ \\
\hline University Students & $8.41(4.05)$ & $8.04(4.17)$ & $9.02(3.99)$ \\
\hline Older Adults & $7.17(3.85)$ & $8.76(3.22)$ & $9.47(2.77)$ \\
\hline Mortuary Students & $6.67(4.97)$ & $5.64(3.52)$ & $7.47(3.16)$ \\
\hline
\end{tabular}

not explain all instances of disgust but merely those in response to symbolic threats posed by reminders of the similarity between humans and other animals. Previous research by Goldenberg et al. [6] also found that mortality salience increased disgust sensitivity only on a limited number of items related to animals and body products. These authors suggested that some stimuli elicit disgust out of distaste or moral revulsion; whereas, others elicit disgust because they remind people of their creatureliness. They further posited that reminders of death increase disgust sensitivity only in response to this latter class of stimuli that remind people of their animal nature and consequently their mortality.

The finding in the present study that mortality salience increased disgust only in response to animals is consistent with previous research that demonstrated the human tendency to deny our creatureliness as a way of abating existential anxiety. For example, reminders of death led participants to prefer the author of an essay arguing for human uniqueness over the author of an essay arguing that humans are similar to other animals [6]. In addition, priming the similarity between humans and other animals prior to the presentation of disgusting stimuli increased the accessibility of death related thoughts [13]. Further, mortality salience in conjunction with priming human-animal similarity led participants with low levels of trait self-esteem to evaluate animals in general more negatively [33].

Although in the present study mortality salience increased disgust sensitivity only in response to items about animals, it is important to note that this effect was unique to death concerns and occurred even among older adults and mortuary students. Whereas uncertainty has been documented to produce effects similar to mortality salience regarding cultural worldview defense [21, 22], the present study found that mortality salience but not uncertainty produced increased disgust sensitivity in response to animals. Uncertainty may activate a need for cognitive certainty that is translated into derogation of those who threaten the validity of an individual's cultural worldview. However, from the perspective of Terror Management Theory [34], the most important function of cultural worldviews is that they ameliorate death anxiety by allowing human existence to be perceived as more significant and enduring than that of other animals. Consequently it is only reminders of mortality and not uncertainty which motivate the desire to maintain the human-animal distinction.

The effects of mortality salience on animal disgust sensitivity were observed not only among university students but also among older adults and mortuary students. This finding is interesting given that the latter two groups have been shown to typically hold more accepting and less anxious attitudes towards death [14-16, 23, 24]. No previous research known to the authors has examined the effects of mortality salience on mortuary students. The fact that mortuary students showed the same reaction to mortality salience as did university students suggests that they still utilize terror management defenses. The interesting implication for Terror Management Theory generally is that even people who have high chronic exposure to thoughts of death and who presumably have little dispositional aversion to thoughts of death still need to employ distal or symbolic psychological defenses when confronted with their mortality. Although previous researchers [18] reported that mortality salience did not produce cultural worldview defense among older adults, the present findings seem to indicate that older adults are not immune to the effects of mortality salience. Older adults may refrain from derogating others as a means of abating existential anxiety, in order to avoid the negative affective consequences. However, they may still need to employ other psychological defenses such as rejecting the creatureliness of the human condition.

In conclusion, the Terror Management perspective does seem to offer a very real account of disgust in response to a small subset of disgust elicitors related to animals. Although disgust in response to a wide range of stimuli, including animals, likely evolved and continuous to function as a means of disease avoidance, disgust in response to animals also seems to serve a psychological function of dampening existential anxiety by maintaining the sense of human distinctiveness, in which people are perceived as more valuable and enduring than other animals.

\section{ACKNOWLEDGMENTS}

This research was supported by a Psi Chi Faculty Advisor Research grant awarded to the first author.

The authors would like to thank Patty Hutcheson and Dennis Flahive for their assistance with data collection at Gupton-Jones College of Funeral Service, Sarah Fletcher for her help with data collection through the FULIR program, and Harrison Kilpatrick at UMPI for his help with data collection and data entry.

\section{REFERENCES}

[1] Curtis V, Aunger R, Rabie T. Evidence that disgust evolved to protect from risk of disease. Proc R Soc Lond B Biol Sci 2004; 271 (Suppl 4): 131-3.

[2] Fessler DMT, Navarrete CD. Domain-specific variation in disgust sensitivity across the menstrual cycle. Evol Hum Behav 2003; 24: 406-17.

[3] Fessler DMT, Navarrete CD. The effects of age on death disgust: challenges to terror management perspectives. Evol Psychol 2005; 3: 279-96. 
[4] Oaten M, Stevenson RJ, Case TI. Disgust as a disease avoidance mechanism. Psychol Bull 2009; 135: 303-21.

[5] Goldenberg JL. The body stripped down: an existential account of the threat posed by the physical body. Curr Dir Psychol Sci 2000; 14: 224-8.

[6] Goldenberg JL, Pyszczynski T, Greenberg J, Solomon S, Kluck B, Cornwell R. I am not an animal: mortality salience, disgust, and the denial of human creatureliness. J Exp Psychol Gen 2001; 130: 42735.

[7] Rozin P, Haidt J, McCauley CR. Disgust. In: Lewis M, Haviland J, Eds. Handbook of emotions, $2^{\text {nd }}$ ed. UK: Guilford Press 2000; pp. 637-53.

[8] Rozin P, Millman L, Nemeroff C. Operation of the laws of sympathetic magic in disgust and other domains. J Pers Soc Psychol 1986; 50: 703-12.

[9] Haidt J, Rozin P, McCauley CR, Imada S. Body, psyche, and culture: the relationship between disgust and morality. Psychol Dev Soc J 1997; 9: 107-31.

[10] Haidt J, McCauley CR, Rozin P. Individual differences in sensitivity to disgust: a scale sampling seven domains of disgust elicitors. Pers Individ Dif 1994; 16: 701-13.

[11] Solomon S, Greenberg J, Pyszczynski T. Terror management theory of self-esteem. In: Snyder CR, Forsyth D, Eds. Handbook of social and clinical psychology: the health perspective. UK: Pergamon Press 1991; pp. 21-40.

[12] Pyszczynski T, Greenberg J, Solomon S. A dual-process model of defense against conscious and unconscious death-related thoughts: an extension of terror management theory. Psychol Rev 1999; 106: 835-45.

[13] Cox CR, Goldenberg JL, Pyszczynski T, Weise D. Disgust, creatureliness, and the accessibility of death-related thoughts. Eur J Soc Psychol 2007; 37: 494-507.

[14] Thorson JA, Powell FC. A revised death anxiety scale. In: Neimeyer RA, Ed. Death anxiety handbook: research, instrumentation, and application. Taylor Francis J 1994; pp. 31-43.

[15] Thorson JA, Powell FC. Death anxiety in younger and older adults. In: Tomer A, Ed. Death attitudes and the older adult. UK: BrunnerRoutledge 2000; pp. 123-36.

[16] Wong PTP, Reker GT, Gesser G. Death attitude profile-revised: A multidimensional measure of attitudes toward death. In: Neimeyer RA, Ed. Death anxiety handbook. Taylor Francis J 1994; pp. 12148.

[17] McCoy SK, Pyszczynski T, Solomon S, Greenberg J. Transcending the self: A terror management perspective on successful aging. In: Tomer A, Ed. Death attitudes and the older adult. UK: BrunnerRoutledge 2000; pp. 37-63.

[18] Maxfield M, Pyszczynski T, Kluck B, Cox CR, Greenberg J, Solomon S, Weise D. Age-related differences in response to thoughts of one's own death: Mortality salience and judgments of moral transgressions. Psychol Aging 2007; 22: 341-53.
[19] Carstensen LL. Evidence for a life-span theory of socioemotional selectivity theory. Curr Dir Psychol Sci 1995; 4: 151-56.

[20] McGregor I, Zanna MP, Holmes JG, Spencer SJ. Compensatory conviction in the face of personal uncertainty: Going to extremes and being oneself. J Pers Soc Psychol 2001; 80: 472-88.

[21] van den Bos K, Euwema MC, Poortvliet PM, Maas M. Uncertainty management and social issues: Uncertainty as an important determinant of reactions to socially deviating people. J Appl Soc Psychol 2007; 37: 1726-56.

[22] van den Bos K, Poortvliet PM, Maas M, Miedema J, van den Ham E. An enquiry concerning the principles of cultural norms and values: The impact of uncertainty and mortality salience on reactions to violations and bolstering of cultural worldviews. J Exp Soc Psychol 2005; 41: 91-113.

[23] Bassett JF, Dabbs JM. Evaluating explicit and implicit death attitudes in funeral and university students. Mortality 2003; 8: 352-71.

[24] Bassett JF, Williams JE. Personification of death as seen in adjective check list descriptions among funeral service and university students. Omega 2003; 45: 23-41.

[25] American Psychological Association. Ethical principles of psychologists and code of conduct. Am Psychol 2002; 57: 1060-73.

[26] Rosenblatt A, Greenberg J, Solomon S, Pyszczynski T, Lyon D. Evidence for terror management theory I: The effects of mortality salience on reactions to those who violate or uphold cultural values. J Pers Soc Psychol 1989; 57: 681-90.

[27] Van den Bos K. Uncertainty management: The influence of uncertainty salience on reactions to perceived procedural fairness. J Pers Soc Psychol 2001; 8: 931-41.

[28] Hirschberger G, Ein-Dor T. Does a candy a day keep the death thoughts away? The terror management function of eating. Basic Appl Soc Psychol 2005; 27: 179-86.

[29] Watson D, Clark LE, Tellegen A. Development and validation of brief measures of positive and negative affect: The PANAS scales. J Pers Soc Psychol 1988; 54: 1063-70.

[30] Greenberg J, Pyszczynski T, Solomon S, Simon L, Breus M. Role of consciousness and accessibility of death-related thoughts in mortality salience effects. J Pers Soc Psychol 1994; 67: 627-37.

[31] Pyszczynski T, Greenberg J, Solomon S. Why do we need what we need? A terror management perspective on the roots of human social motivation. Psychol Inq 1997; 8: 1-20.

[32] Olatunji BO, Williams NL, Tolin, DF, Abramowitz JS, Sawchuck CN, Lohr JM, Elwood LS. The disgust scale: Item analysis, factor structure, and suggestions for refinement. Psychol Assess 2007; 19: 281-97.

[33] Beatson RM, Halloran MJ. Humans rule! The effects of creatureliness reminders, mortality salience, and self-esteem on attitudes towards animals. Br J Soc Psychol 2007; 46: 619-32.

[34] Schimel J, Hayes J, Williams T, Jahrig J. Is Death really the worm at the core? Converging evidence that worldview threat increases death-thought accessibility. J Pers Soc Psychol 2007; 92: 789-803. 